\title{
AN IMPLEMENT FOR MECHANIZATION OF OLEAGINOUS ROSE HARVESTING
}

\author{
Snezhan Bozhkov, Miho Mihov, Emanuel Badrikov, Stanislav Stanchev \\ Institute of Soil Science, Agrotechnologies and Plant Protection "Nikola Pushkarov" \\ 7, "Shosse Bankya str., POBox 1369, Sofia 1331, Bulgaria \\ tel. (359 2) 8246141, e-mail: soil@mail.bg
}

\begin{abstract}
The only stage in the cultivation of oleaginous rose, in which even today all activities continue to be performed manually, is the rose flowers harvesting.

The report presents the final results of the stage "forming a concept on the construction of an implement for mechanization of oleaginous rose harvesting". A technical solution is proposed that solves complex the problems related to the working conditions of pickers and productivity of technological operation by realizing the pneumatic picking of rose flowers and transportation of the pickers and collected by them production in the rows of rose plantation.
\end{abstract}

Keywords: oleaginous rose, rose flower, harvesting, mechanization, implement, working conditions, productivity.

\section{INTRODUCTION}

The oleaginous rose has always been a subject of national pride for Bulgarian nation as well as a symbol of the republic of Bulgaria within the international communion. The essential oil extracted from this kind of rose has characteristics that excels the rose oils offered on international market by other manufacturing countries such as Turkey, Russia, China, Iran, India, Georgia, Egypt, Algeria and France.

Nowadays a number of technological operations in the cultivation of the oleaginous rose are partially or fully mechanized $[3,4]$. The activities, related to the preparation of the site for a new plantation, the replanting of stem cuttings, the annual soil cultivation including ploughing, line hoeing, earthing, manuring, fertilization, chemical control of weeds, diseases and pests, pruning after rose harvesting have already been mechanized. The only stage in the technological process, in which all activities are performed manually, is harvesting.

The picking of the oleaginous rose is carried out by workers under unfavourable conditions. The rose flowers are collected in the blooming phase when the basic accumulation of essential oil occurs. The rose harvesting lasts about one month - from mid-May until midJune. It begins in the early morning at high ambient humidity caused by the falling morning dew and the frequent rainfall of the period. The rose pickers advance along the row spacing by performing multiple moves "back and forth" and often carry the harvested flowers "on their back" to the collection point outside the rose plantations. The thorns of the rose plants and the stinging insects hidden in the rose flowers create some extra problems.

Information concerning the conduct of large-scale researches on mechanization of the oleaginous rose harvesting is missing in the international scientific area. There are studies on the separation of petals from the rose flowers [5, 9]. According to information from the Institute of Roses, Essential and Medical Cultures in Kazanlak an attempt to ease harvesting of the oleaginous rose have been made in Bulgaria in the recent past. Research that has led to the invention and implementation into production of a farm machine for mechanized 


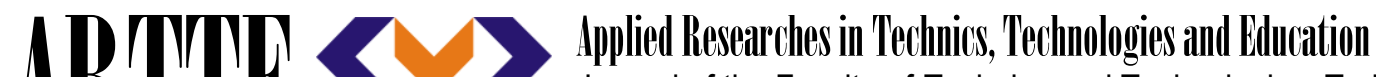 Journal of the Faculty of Technics and Technologies, Trakia University https://sites.google.com/a/trakia-uni.bg/artte/}

harvesting of the blooming rose flowers has not been found out either in Bulgaria or in other countries where oleaginous rose is traditionally grown [2, 4].

The aim that the working team of science section "mechanization" of IPAZR "N.Pushkarov"Sofia set itself was the development of an implement for mechanization of oleaginous rose harvesting with which to improve the working conditions of pickers and raise labor productivity of technological operation.

\section{METHODS}

The results of the research presented in [2] can serve as basis for the invention of an implement for mechanized harvesting of the oleaginous rose by pneumatic picking of the rose flowers. Considering the morphological characteristics of the oleaginous rose, the specifics of the process of rose harvesting and the requirements to the mobile power means for forming of tractor/implement combination for mechanization of the harvesting process, a scheme of an implement which transports the pickers and harvested produce along the row spacing during the rose harvesting has been developed. The implement eliminates the need for self-movement of the pickers with the harvested rose flowers "on their back" along the row spacing of rose plants. Their participation in the process consists in handpicking of the rose flowers (as it is in traditional rose harvesting) and dropping them in the nearby container for storing the collected produce.

It is logical to assume that the working conditions for rose pickers will be improved even more, and the productivity of the tractor/implement combination will be increased in case the handpicking of the rose flowers is also mechanized. An appropriate technical solution could be found by using the potentials of vacuum, the application of which in picking and transporting systems is not a novelty in agricultural practice.

Approaches to develop a conceptual design for a technical device to replace the hand picking off, could be two:

- Approach 1 (defined as energy-saving), in which the technical device allows all petals and most of the other components of the rose flowers to be sucked by vacuum, with the exception of sepals;

- Approach 2 (defined as conventional) in which the technical device allows to be realized the traditional practice whereby the rose flowers are collected by picking below the flower cup.

Basis for the adoption of the first (energy-saving) approach is the fact that the essential oil in the flower cup is only $2,3 \%$ of the total amount in the flower and the rest is localized in the petals $(92,8 \%)$, staminal stipe $(4,6 \%)$ and the pistil $(0,3 \%)[7,8]$. It is assumed that the energy for the separation of the petals will be significantly less, and the pluses contributed by pneumatic picking off will compensate the "loss" of rose oil in the remaining non-picked elements of the rose flowers.

Insuperable or hard to overcome problems will need to find the ways to realize the traditional practice of rose harvesting. It is to be expected that the device carrying out the separation of the flowers of rose plant will be considerably more complicated in the structural plan.

In determining the parameters of the pneumatic system for oleaginous rose harvesting, specific peculiarities of the rose flower should be considered including size, weight, shape, picking force, etc. 


\section{ARTTIE $Y$}

Ipplied Resseirlohes in Technics, Technologies and Bductation

Journal of the Faculty of Technics and Technologies, Trakia University https://sites.google.com/a/trakia-uni.bg/artte/

\section{RESULTS}

\subsection{Construction features of the implement for mechanization of the oleaginous rose harvesting}

The overall look of the implement for mechanization of the oleaginous rose harvesting by pneumatic picking of the rose flowers is presented in Figure 1. The main elements and assemblies of its construction are indicated in Figure 1 as well as the rows of rose plantations and the farm tractor to which the implement is mounted for implementation of the harvesting process.

The implement includes carrier frame 9 , in the forepart of which the hitch attachments for connecting to farm tractor 23 is formed. The type and sizes of the hitch attachments of implement's triangle can be made in accordance with the Bulgarian State Standard [1], the international ISO-standard [6] or in a variant, providing an opportunity for attaching to the tractor linkage, made according to both standards.

Operating modules 8 , each of which is situated between two adjacent rows of rose bushes, are fixed to the carrier frame 9 . The number of modules may vary. The operating modules are connected to the carrier frame by fastening units 26 .

Each operating module 8 consists of L-shaped frame 2 (in the medium module there are two of the same kind) and loading platform 3 with a protective parapet 7 located at its perimeter. Two workstations are situated on the platform (rear workstation 10 and front workstation 13) for simultaneous servicing of a half of two adjacent rows of rose plantations. Each workstation includes seat 4 and stand 5 with a removable container for the harvested produce 6 . The stand and container are situated behind the seat of the second workstation. A pneumatic system 16 for picking off and carrying the blooming rose flowers to the container for their storage is also mounted.

The pneumatic picking off system 16 consists of vacuum-pump, manipulators, pneumatic tubes, dispensers, regulator, connecting elements and protective devices. The vacuum-pump 21 provides the needed vacuum in the system for implementation of the picking of the rose flowers, and regulator 22, situated next to it allows for the vacuum rate to be keyed as appropriate for the particular conditions. The vacuum-pump is fixed in close proximity to the shaft power take-off (PTO) 20 of the tractor and is driven by it.

The central vacuum tube 19 connects the vacuum-pump 21 with the central dispenser 18 , the sectional vacuum-tubes connect the central dispenser 18 with the sectional dispenser 14; container vacuum tubes 25 connect the sectional dispensers 14 with the removable containers 6 . On each of the removable containers there is a sealing cover 27 with a built-in relief valve 28. Manipulator's vacuum tube 29 connects the sealing cover with manipulator 30. The pneumatic tubes connecting the vacuum-pump with the central dispenser and the manipulators with containers' covers are flexible. The rest of the pneumatic tubes can be non-deformable.

Luminaries 15 are fixed on the carrier frame. Their electric supply is implemented by the electrical equipment of the farm tractor.

The support wheels 12 are fixed by console structures 11 to the lower end of L-shaped frames of the side operating modules (the upper ends are connected to carrier frame 9). 


\section{ARTTLY $Y$}

Ipplied Resseirl'hes in Technics, Technologies and Bductation Journal of the Faculty of Technics and Technologies, Trakia University https://sites.google.com/a/trakia-uni.bg/artte/
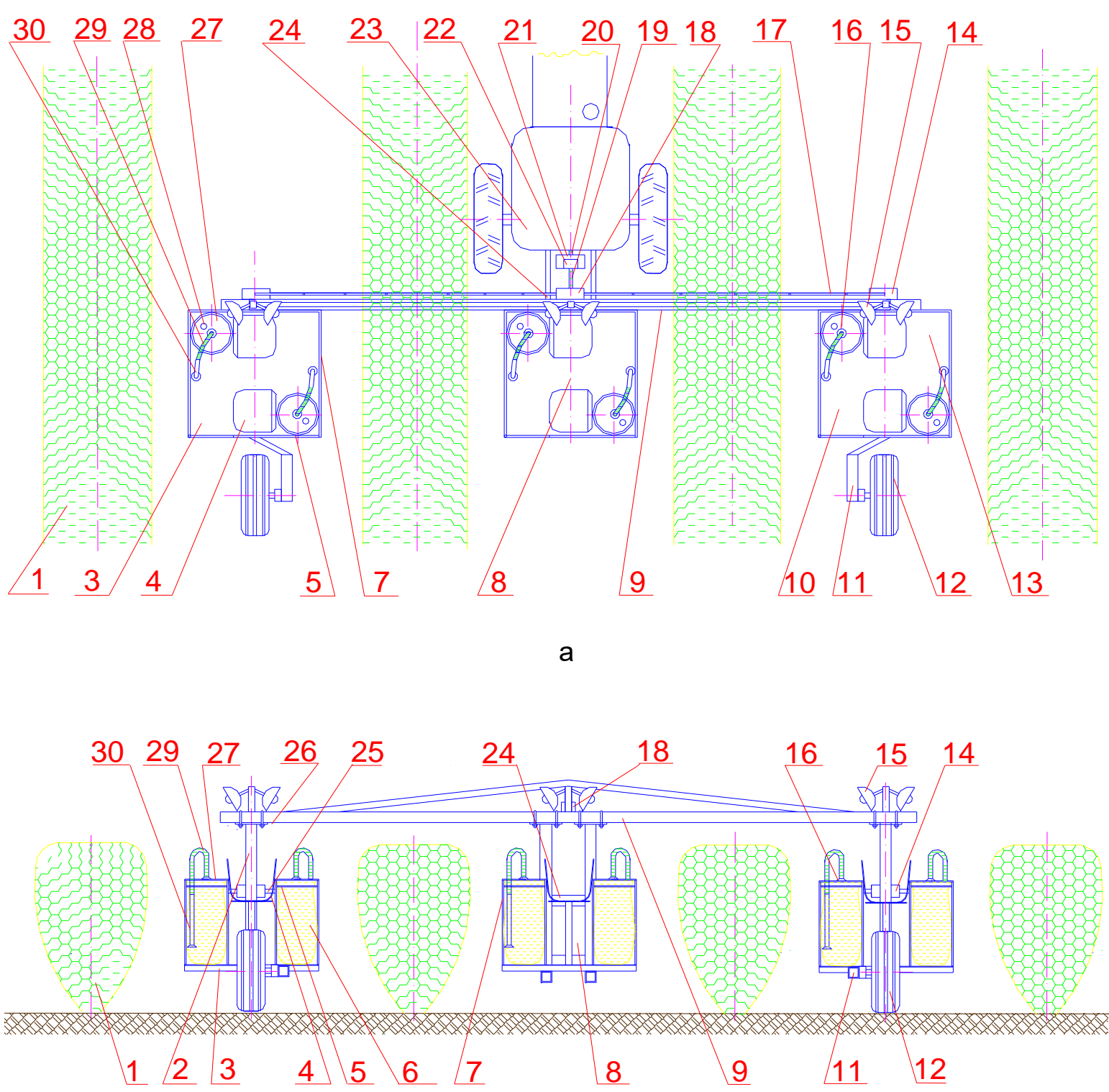

8

$\begin{array}{lll}9 & 11 & 12\end{array}$

b

Figure 1. Scheme of an implement for mechanization of oleaginous rose harvesting with pneumatic picking of the rose flowers

a) View from above b) View from behind

1 - row of rose bushes; 2 - L-shaped frame; 3 - loading platform; 4 - picker's seat; 5 - stand for the removable container; 6 - removable container for the harvested rose flowers; 7 protective parapet; 8 - operating module; 9 - carrier frame; 10 - rear workstation; 11 console structure; 12 - support wheel; 13 - front workstation; 14 - sectional way distributor; 15 - luminaries; 16 - pneumatic picking off system; 17 - sectional vacuum tube; 18 central dispenser, 19 - central vacuum tube; 20 - shaft of Power take-off; 21 - vacuumpump; 22 - vacuum regulator; 23 - farm tractor; 24 - hitch attachments of implement's triangle; 25 - container vacuum tube; 26 - fastening unit; 27 - sealing cover; 28 - relief valve; 29 - manipulator's vacuum tube; 30 - manipulator.

IRITIE Vol. 5, No. 3, 2017 ISSN 1314-8788 (print), ISSN 1314-8796 (online), doi: 10.15547/artte.2017.03.001 


\section{ARTTIE $Y$}

Ipplied Resseirl ches in Technics, Technologies and Bductation

Journal of the Faculty of Technics and Technologies, Trakia University https://sites.google.com/a/trakia-uni.bg/artte/

\subsection{Practical use of the implement for mechanization of the oleaginous rose harvesting}

The implement for mechanization of the harvesting of the oleaginous rose is used in the agricultural production after its attaching to a farm tractor.

Regulating the distance between the operating modules 8 , according to the width of the space between rose plantation rows, are done using the fastening units 26 , which are fixed to carrier frame 9 .

The tractor/implement combination completed with the pickers in their working places moves in the rose plantations at a forward speed, which allows the harvesting of all possible produce. Each of the pickers directs controlled by him manipulator 30 to a blooming rose flower. The vacuum created by vacuum pump 21, having reached the vacuuming part of manipulator 30 along the whole chain of dispensing and connecting elements of the pneumatic picking off system, picks the flower and through vacuum tube 29 transports it to removable container 6 storing the harvested produce. After the removable containers are filled with rose flowers, they are replaced by empty ones.

During the longest part of the picking process the workers are seated, which provides the necessary stability and preserves their efficiency. The pickers' safety during the working process is ensured by protective parapet 7 fixed to the loading platform. The size and type of the parapet do not prevent the blooming roses from being harvested. The protective parapet restricts undesirable contact of the pickers with the rose bushes by removing the last while the tractor/implement combination is moving in the spacing of rose plantations.

In the early hours before sunset the harvested by the pickers sections of the rose plantations are illuminated by luminaries 15 . The direction of the scintillated luminous flux can be adjusted.

\section{CONCLUSIONS}

A decisive step to raising the efficiency of rose production can be done by mechanization of the picking of the rose flowers - the only stage in the technological process that even nowadays continues to be performed manually. The presented results of research that has been conducted in the Mechanization, Irrigation and Drainage Department of Nikola Pushkarov Institute of Soil Science, Agrotechnologies and Plant Protection are definitive for the stage "forming a concept about the construction of an implement for harvesting of oleaginous rose". The opportunities that the implement reveals such as improving the working conditions, eliminating the non-productive idling, providing sufficient technological time for harvesting of a product, which is extremely demanding to production conditions, accelerating of the harvesting process, easing the selection of qualified and responsible rose pickers and etc. will lead to higher efficiency of labor in harvesting the rose flowers and will enable the Republic of Bulgaria to uphold its reputation as a world leader in the production of oil from oleaginous rose.

\section{REFERENCES}

[1] BDS 15648-83 Agricultural tractors and machinery. Mounted system. Three-point linkage device. Joining dimensions (BG).

[2] Bozhkov, S., E.Badrikov, S., Mihov, M. and Bozhkova, O., 2012. Substantiation of parameters of the machine for harvest mechanization of rose petals. Proceedings of the technical and scientific conference ECO-Varna, 10 - 12 May 2012, Varna, Bulgaria, pp.61-71 (BG).

IRTTIE Vol. 5, No. 3, 2017 ISSN 1314-8788 (print), ISSN 1314-8796 (online), doi: 10.15547/artte.2017.03.001 


\section{ARTTIE $Y^{2}$}

Ipplied Resseirl'hes in Teednicis, Technologies and Bductition

Journal of the Faculty of Technics and Technologies, Trakia University https://sites.google.com/a/trakia-uni.bg/artte/

[3] Nedkov, N. and Kovacheva, N., 2011. Creation and growing of oleaginous rose plantations. Agronomist, №4, (BG).

[4] Stanchev, S., 2015. Mechanization of oil rose growing - state, problems, perspectives. Agricultural machinery, 1, pp. 16-18, (BG).

[5] Patent Database of the USSR, 1940. Device for separation of petals from the rose flowers. Declared August 261940 under the number 2771 in the People's Commissariat of Food Industry, (RUS).

[6] ISO 730:2009 Argicultural wheeled tractors - Rear-mounted three-point linkage Categories $1,1 \mathrm{~N}, 2,2 \mathrm{~N}, 3,3 \mathrm{~N}, 4$ and $4 \mathrm{~N}$.

[7] http://www.savetivzemedelieto.bg/topic/maslodajna roza. 14.07.2014.

[8] http://cvetya.com/agrotehnika-za-kazanlashkata-roza/.

[9] Yilmaz, D., Ekinci, K. 2011. Physico-mechanical characteristics of rose petals dealing with the pneumatic harvest of Rosa damascena/ Span J Agric Res, 9(2), 389-394, ISSN: 1695-971-X. 